Article

\title{
Remote Sensing-Based Exploration of Structurally-Related Mineralizations around Mount Isa, Queensland, Australia
}

\author{
Sandra Jakob ${ }^{1, *}$, Richard Gloaguen ${ }^{1}$ and Carsten Laukamp ${ }^{2}$ \\ 1 Helmholtz Zentrum Dresden Rossendorf, Helmholtz Institute Freiberg for Resource Technology, Division \\ “Exploration Technology", Chemnitzer Str. 40, 09599 Freiberg, Germany; r.gloaguen@hzdr.de \\ 2 CSIRO Mineral Resources, 26 Dick Perry Avenue, Kensington, WA 6151, Australia; \\ carsten.laukamp@csiro.au \\ * Correspondence: s.jakob@hzdr.de; Tel.: +49-351-260-4419
}

Academic Editors: Ruiliang Pu, Magaly Koch and Prasad S. Thenkabail

Received: 25 February 2016; Accepted: 21 April 2016; Published: 25 April 2016

\begin{abstract}
Hyperspectral imaging is a powerful tool for mineral mapping and increasingly used in poorly-accessible areas. It only requires a limited amount of validation sample points, but can fail to discriminate spectrally-similar features. In this manuscript, we show that we improve the identification of interesting targets by including geomorphological data in the spectral mapping scheme. We jointly use geomorphic and spectral features to locate gossanous ironstone ridges as an indicator for possible $\mathrm{Pb}-\mathrm{Zn}-\mathrm{Ag}$-mineralization and provide an application around Mount Isa and George Fisher/Hilton mine, Queensland, Australia. We combine hyperspectral HyMap data using mixture tuned matched filtering with topographical indices, such as maximum curvature and the topographical position index. As it is often the case with structurally-controlled mineralization, the amount of training sites is limited, and supervised classification methods cannot be implemented. Therefore, we implement expert knowledge in a decision tree to take advantage of the relationship between mineralization, alteration and structure. Optimized rock sampling and spectral measurements provided data for validation. We are able to map sets of gossanous ridges with a minimum of validation points, not only within the Mount Isa mining area itself, but also outside the commonly-accepted host rocks. The ridges are parallel to north-south trending geomorphological features and probably associated with the Paroo fault zone. Similarities between the ridges were confirmed by field observations, spectral measurements and a qualitative rock sample analysis. We identified new mineralized ridges that we could subsequently attribute to a poorly-known and sub-economic deposit known as the Mount Novit Pb-Zn-deposit.
\end{abstract}

Keywords: HyMap; hyperspectral; mineral mapping; geomorphological features; alteration mapping

\section{Introduction}

One of the most important applications of remote sensing techniques is the investigation of distant and/or barely-accessible areas. It can provide geologically-relevant information about the occurrence, distribution and relationship of minerals and lithologies, as well as structural and geomorphological features. Remote sensing techniques support the exploration process, even when rugged terrain, vegetation, distance and prohibited areas may limit the amount of training and/or validation sites. Exploration of mineral deposits usually implies extensive surveys, including geophysical, as well as geochemical analysis and drilling. To lower the cost and potential impact on the environment, it is advisable to increase efficiency by limiting the study area to promising exploration sites and only a few, well-chosen drill sites. The use of hyperspectral data for mineral or alteration mapping is 
common. Similar to multispectral remote sensing, hyperspectral imaging aims to collect and process electromagnetic spectral data, but with an increased spectral resolution due to a high amount of narrow, discrete bands. This makes determination of type, abundance and distribution of more minerals or materials possible, when compared to multispectral systems. Especially in sparsely-vegetated areas, it can be used to determine the type and distribution of alteration minerals.

Remote sensing-based surveys for mineral exploration are often limited to the use of spectral information only, e.g., [1-4]. Even if this approach achieves good results for certain types of distinct minerals, it hits the wall at the discrimination of materials with similar spectral features. Therefore, combining spectral with other remote sensing data types is increasingly used to enhance mineral mapping performance. Therefore, e.g., Azizi et al. [5] combined hyperspectral and aeromagnetic data for mineral and structural mapping, while Bersi et al. [6] used multispectral and aerogravity data for the exploration of iron deposits. However, the combination of spectral and geomorphological data is a yet seldom used, but promising approach for the mapping of geomorphologically-prominent deposits. A successful implementation of this approach would not only help with distinguishing mineralized zones from spectrally-similar structures, like debris or river fillings, but also draw conclusions about their structural relationship. The main objective of the present study is to determine (1) whether common hyperspectral mineral mapping can be improved by implementing geomorphological data and (2) if and how the common exploration process can be facilitated by this approach, even in areas where the amount of training sites is inherently low. A reduced amount of validation and training sites can result from area inaccessibility and/or due to the geometry of the mineral deposits (e.g., narrow veins, dykes, ridges).

\section{Study Area}

We chose the example of the Mount Isa Mining Complex within the Mount Isa Inlier, Northwestern Queensland, Australia (Figure 1). The region is known for the considerable ore deposits and the consequent mining of copper, zinc, lead and silver [7]. The occurring mineralization is related to structures and often shows a clear geomorphological expression as prominent ironstone ridge [8]. The region of interest is barely accessible, not only because of natural circumstances, but also because the mining operation area prohibits the access to nearly all ironstone outcrops. The area was thoroughly investigated by many groups, mainly concerning regional geology, structure and economic geology; therefore, it holds a huge data basis, e.g., [8-12]. Hyperspectral, as well as digital elevation data are available; however, only a limited number of remote sensing surveys have been published for that area. A comprehensive survey using hyperspectral HyMap and multispectral ASTER data for mineral mapping was carried out by Cudahy et al. [13], delivering a set of publicly-available mineral mapping products covering parts of Queensland, especially the Mount Isa Inlier. The same data basis was used by Yang et al. [14], Laukamp et al. [3] and Laukamp et al. [15] to investigate alteration zones and patterns within the Mount Isa Inlier. In Perera et al. [16], multi-source spatial data were used for land cover classification. Until now, an implementation of spectral and geomorphological data for mineral mapping has not been conducted. The present study attempts to use this approach for the mapping of gossanous outcrops near Mount Isa mine, which can be an indication of underlying deposits. Previous knowledge from available geological maps or publications, as well as preliminary remote sensing results help to define sampling areas for a field campaign. The fieldwork provides rock samples and in situ spectral measurements for the definition of the gossan-associated spectral endmember, which is afterwards used for a partial unmixing of HyMap hyperspectral data. The mapping results are combined with calculated topographic indices for optimization and further differentiation. Due to the quite low amount of available training sites, no statistical learning-based classification methods are used. Instead, the gathered expert knowledge provides the basis for a classification using a decision tree. The mapped potential gossanous outcrops can subsequently be validated by transect sample points and the occurrence of mineralization described in the literature. Such a validation happened fortuitously during this study as we independently rediscovered the Mount Novit range deposit. We 
were not aware of the existence of this deposit during the entire procedure, mostly due to its very sparse documentation in published work; it gave us the opportunity for a perfect validation.

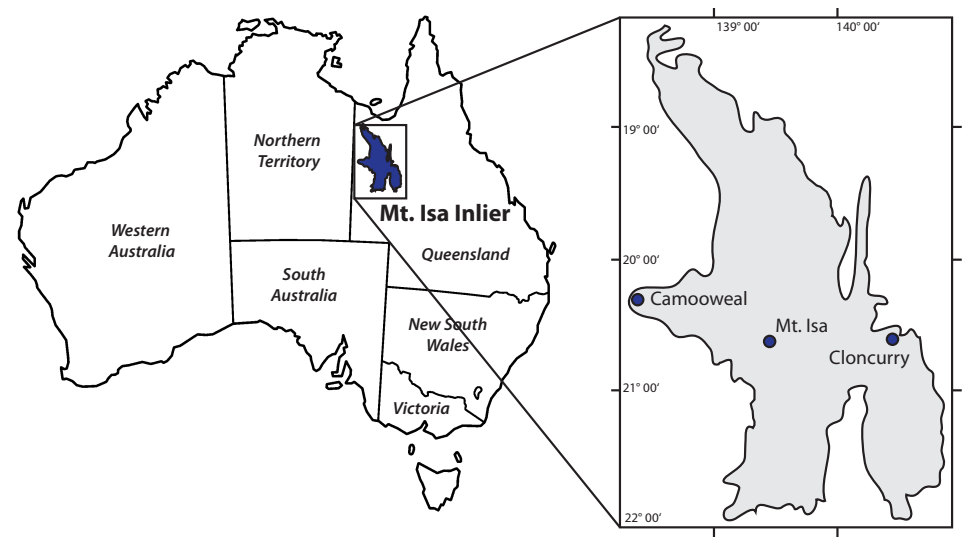

Figure 1. Location of the Mount Isa Inlier within Australia.

\section{Regional Geology}

The Mount Isa Inlier can be spatially divided into several meridional belts, which are separated by major north-striking strike-slip fault zones or faults. Each of these zones has, to some degree, a differing Proterozoic stratigraphy, compared to the neighbour cluster. According to Stewart and Blake [11], those tectonic units are the Western Fold Belt, the Kalkadoon-Leichhardt Belt and the Eastern Fold Belt (Figure 2). The Proterozoic tectonostratigraphy of the Mount Isa Inlier is subdivided into two main cycles, which are separated by the Barramundi Orogenic Event at 1900-1870 Ma [17]. While the basement unit represents the first cycle, the second cycle includes three main cover sequences. The latter ended between 1620 and 1520 Ma with a region-wide metamorphism and deformation event, called Isan Orogeny [7]. The sparsely outcropping basement includes the oldest exposed lithological units and comprises sedimentary, volcanic and intrusive rocks. The three overlying cover sequences are several kilometres thick, stratigraphic packages of a mainly fluvial to lacustrine or shallow-marine depositional environment [11]. Igneous activity in the Mount Isa Inlier is complex, starting with the 1870 Ma Barramundi Orogeny and ending up with the emplacement of dolerite dykes at around 110 Ma. A detailed description of the regional geology of the Mount Isa Inlier can be found in Blake [7] and Stewart and Blake [11].

The study area was set around the geological sequence hosting the biggest and most important mining complex of the Mount Isa Inlier, the Mount Isa Mines, neighbouring to the west of the same-named city. All three mines in this area, Mount Isa, George Fisher and Hilton, are hosted by the Urquhart Shale Formation, which is part of the Mount Isa Group (3). Its 5 km-thick sequence consists of weakly-metamorphosed, mid-Proterozoic carbonate siltstones, mudstones and shales and is located in the hanging wall of the synextensional Paroo Fault (Figure 2). This large-scale normal fault forms a ramp-like basement structure underlying all major copper orebodies at Mount Isa mine. The foot wall is composed of the altered metasediments and metabasites of the older Cromwell metabasalt, which is part of the Eastern Creek Volcanics Formation. Primary copper ore is restricted to a rock variant of the Urquhart shale, the so-called silica dolomite. It forms a highly variable, tongue-shaped body, consisting mainly of brecciated shale remnants, coarse crystalline dolomite and macroscopic quartz [9,18]. Pb-Zn-Ag orebodies are situated in the upper $650 \mathrm{~m}$ of the Urquhart Shale extending $1.2 \mathrm{~km}$ down dip and $1.6 \mathrm{~km}$ along strike, containing galena, sphalerite, tetrahedrite, pyrite, pyrrhotite and freibergite [9]. In contrast to the primary copper ore, the lead-zinc-silver orebodies are compositionally similar to the shales (except the additional mineralization) and consist of small definite stratigraphic horizons [19].Whenever these ore-containing horizons reach a certain density, they form an orebody [18]. The thickness of the single ore lenses is mostly ranging within the centimetre- to 
decimetre-scale, but can also reach up to $50 \mathrm{~m}$ at the so-called Black Star deposit. The ore loads and pyrite lenses do not persist to the surface, but find their expression as silicified and ferruginous gossans, which form 1-5 $\mathrm{m}$ high strike-parallel rib-like ridges situated on low hills that rise 5-25 $\mathrm{m}$ above the alluvial flats.

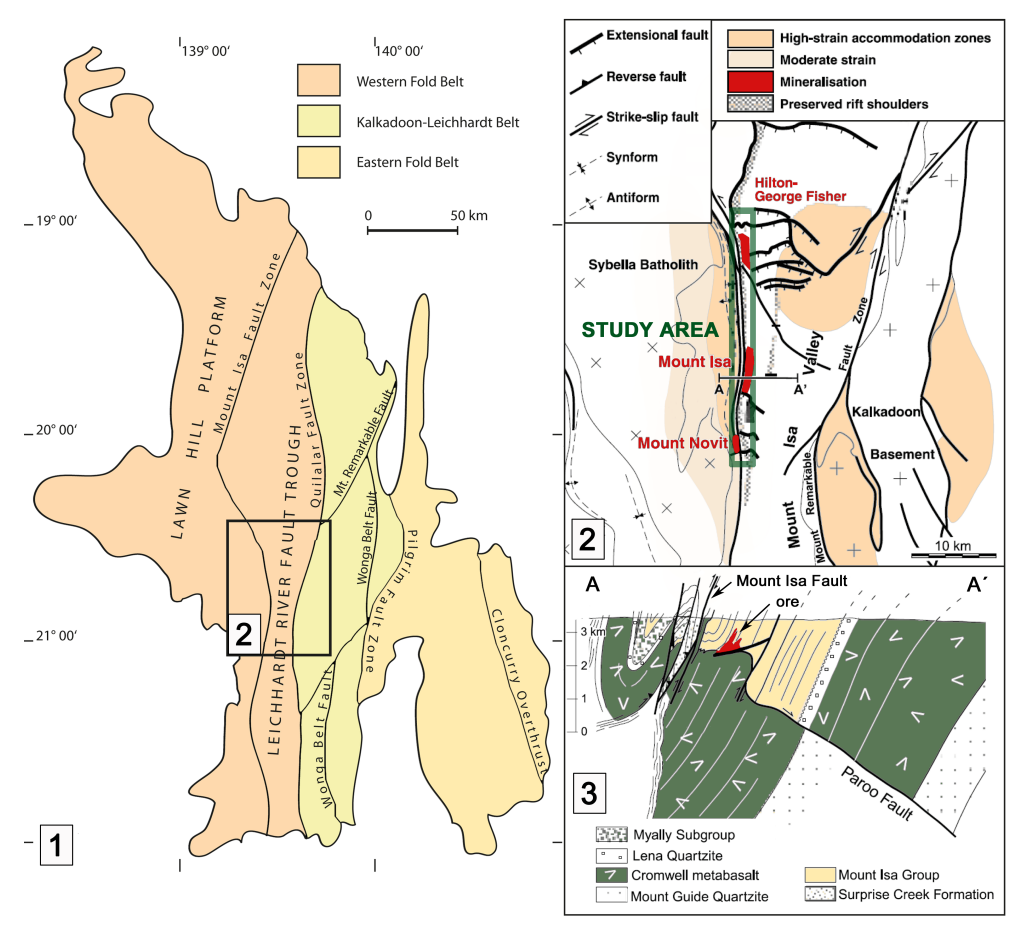

Figure 2. Tectonic and stratigraphic units of the Mount Isa Inlier: (1) tectonic zones and main faults after Blake [7] and Stewart and Blake [11]; (2) tectonic overview of the Mount Isa Valley, including strain and mineralization, zones after Betts and Lister [20]; (3) cross-section of the Mount Isa Valley as indicated in (2), after Betts and Lister [20].

Today, in 2016, at Mount Isa, Pb-Zn-Ag is open-pit mined from the Black Star deposit, while copper ore is processed from the underground X41 and Enterprise lodes. The Hilton and George Fisher $\mathrm{Pb}-\mathrm{Zn}-\mathrm{Ag}$ deposits to the north of Mount Isa were discovered in 1947; the related George Fisher mine was opened in 1990; the adjacent Handlebar Hill open pit commenced in 2007. The Mount Novit horizon is situated about 15-20 km south of Mount Isa city within the Breakaway Shale and Native Bee Siltstone (Figures 2 and 3). It comprises a $20 \mathrm{~m}$-thick lens of mainly pyrite, pyrrhotite and magnetite and is expressed at the surface as an $8 \mathrm{~km}$-long prominent discontinuous ridge [21]. The mineralization occurs in a stratigraphically lower unit than the Mount Isa and Hilton deposits; nevertheless, Taylor and Scott [21] show that they are at least basically similar regarding average mineralogical and chemical composition. The Mount Novit deposit is commonly classified as sub-economic and barely mentioned in important regional geologic publications. A detailed description of the Mount Novit ore-body can be found in Perkins [22]. 


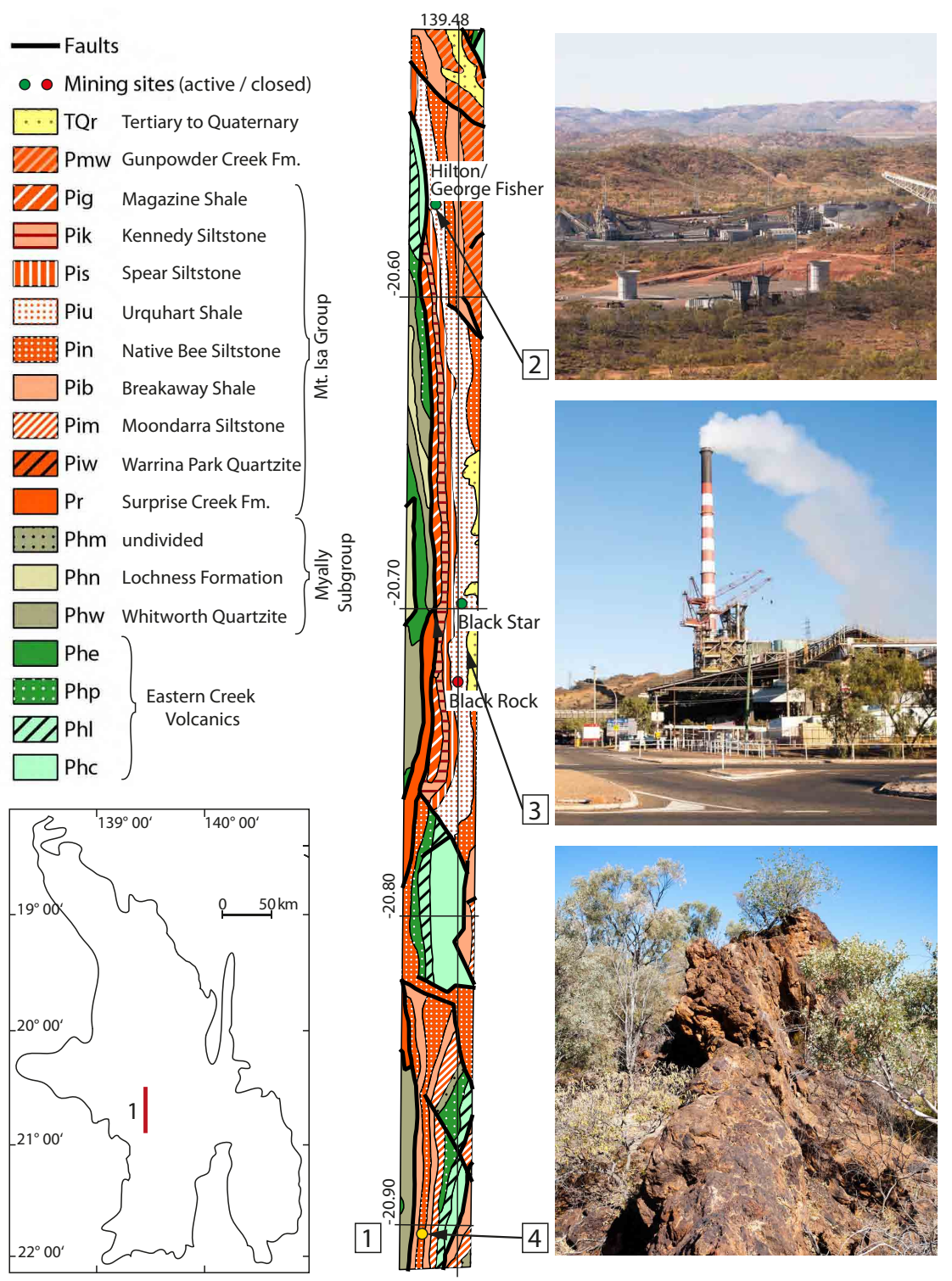

Figure 3. The study area: (1) geological map; (2) view over George Fisher/Hilton mine; (3) copper smelter stack west of Mount Isa; (4) ironstone ridge at the Mt. Novit range deposit. The geological map and abbreviations are derived from Blake [7], Wilson et al. [23] and Grimes et al. [24].

\section{Used Data and Methods}

Due to previous investigations of Australia's Commonwealth Scientific and Industrial Research Organisation (CSIRO) [13], both geomorphological and hyperspectral data are available for the Mount Isa Inlier. While ASTER GDEM digital elevation data continuously cover the whole region, airborne hyperspectral HyMap data are only on-hand for selected areas [13].

\subsection{Hyperspectral Data}

\subsubsection{Sensor and Data Characteristics}

The airborne hyperspectral scanner HyMap is operated by HyVista Corporation and provides 128 contiguous bands covering the reflective solar wavelength region between 0.45 and $2.50 \mu \mathrm{m}$, making it able to provide distinct information for mineral mapping (see the examples in Table 1). 
Table 1. Characteristic wavelengths and related HyMap bands containing specific information used for mineral mapping [25].

\begin{tabular}{lll}
\hline Wavelength Range (nm) & HyMap Bands & Enhanced Material \\
\hline $550-750$ & $8-14$ & charge transfer $\mathrm{Fe}^{3+}-\mathrm{Fe}^{2+}$ \\
$800-1000$ & $25-39$ & crystal field bands $\mathrm{Fe}^{2+}$ \\
$1350-1400$ & band gap & $\mathrm{OH}$ - first overtone \\
$1850-1950$ & band gap & $\mathrm{H}_{2} 0$ \\
2252 & 111 & $\mathrm{AlFe}^{3+}-\mathrm{OH}$ combination \\
2300 & 114 & $\mathrm{Fe}^{3+}-\mathrm{OH}$ combination \\
2346 & 117 & $\mathrm{Mg}-\mathrm{OH}$ combination \\
\hline
\end{tabular}

Only excluded are the atmospheric water vapour bands with $1.35-1.40-\mu \mathrm{m}$ and $1.80-1.95-\mu \mathrm{m}$ wavelengths. The bandwidths vary between 15 and $20 \mathrm{~nm}$. The sensor is mounted on a 3-axis gyro-stabilized platform to reduce image distortions caused by aircraft movement [26]. The used HyMap data stripe was acquired on 20 August 2001, 4:17 (UCT), with an plane altitude of $2.561 \mathrm{~km}$ and an average scene elevation of $376 \mathrm{~m}$. The spatial resolution depends on the flight altitude; for the present data, it accounts for about $2.5 \mathrm{~m}$ per pixel. The data stripe includes 125 spectral bands and has a spatial extent of $3 \mathrm{~km}$ west-east and $66 \mathrm{~km}$ north-south.

The raw HyMap data needs to undergo several preprocessing steps before it can be analysed and interpreted. These steps comprise atmospheric correction, cross track illumination correction (CTI), geometric correction and georeferencing. The current HyMap radiance data are already atmospherically corrected by HyVista Corporation using HyCorr, a software package developed by CSIRO. and hereby converted to surface reflectance. For the CTI an additive 5th order polynomial function is fit in the sample direction to remove the results of non-uniform illumination of the image during the acquisition. Geometric correction and georeferencing are carried out using the provided geometric lookup table, containing information about the association of each pixel to its corresponding output pixel location. Thereby, also distortions caused by variations in speed, altitude and aircraft orientation are compensated [4].

\subsubsection{Mixture Tuned Matched Filtering}

Each pixel of a hyperspectral dataset represents a mixture of component materials, each contributing with its spectral signature to the spectral reflectance of the pixel. The spectral unmixing techniques are used to calculate the relative abundance and spatial distribution of a given number of spectrally unique endmembers within a hyperspectral image. Mixture tuned matched filtering (MTMF) is a special type of partial spectral mixture analysis, as it is capable of unmixing a single endmember from an unknown background. Classic matched filtering (MF) matches the known spectral signature to the image spectra and unmixes it by maximizing the respond of the known endmember in the image while suppressing the response of all unknown composite background. MTMF adds an infeasibility (IF) image to the results of a normal matched filtering. This image decreases the number of false positives, which sometimes occur when using MF. To calculate infeasibility, the input spectra have to be minimum noise fracture (MNF) transformed to provide unit variance $[27,28]$.

\subsection{Geomorphological Data}

For the tectonic geomorphological analysis of the study area, the TPI (topographic position index) and maximum curvature were most suitable for the enhancement of ridges. TPI was calculated in R, and maximum curvature was determined using the Topographic Modeling Toolbox of ENVI 5.1. For that, ASTER GDEM 2 digital elevation data with a resolution of $30 \mathrm{~m}$ were used. This is a product of NASA and METIand was acquired on the 17 October 2011. 


\subsubsection{Topographic Position Index}

The TPI determines the difference between the elevation at a certain central point $z_{0}$ and the average elevation $\bar{z}$ of a neighbourhood within a predetermined radius $R$ by [29]:

$$
T P I=z_{0}-\frac{1}{n_{r}} \sum_{i \in R} z_{i}
$$

Hence, the TPI provides a kind of landscape classification with positive values representing elevations higher than the neighbourhood and negative values when they are lower. In doing so, the results are dependent on $\mathrm{R}$, where large radii highlight major landscape units and smaller values reveal minor valleys and ridges $[29,30]$.

\subsubsection{Maximum Curvature}

The curvature or convexity is provided as a second derivative of elevation. While negative values indicate concave surfaces, convex surfaces have positive curvature values. Therefore, the maximum curvature determines the most convex surfaces, including peaks and ridges. Hereby, it does not regard a distinct direction for the calculation of curvature, but applies to the overall surface within the moving window. The size of this window determines the scale of the detected features [31].

\subsection{Definition of Threshold Values}

To blind out the green vegetation cover, a mask out for NDVI $>0.3$ was applied to the corrected HyMap images [32]. The truly detected pixels containing the target material were extracted from the MTMF result using thresholds. Those can be derived manually from a 2D scatter plot regarding MF score and infeasibility (Figure 4). The background distribution is marked by points with an MF score around and below zero. False positive pixels have high infeasibility values, while correctly-mapped pixels show low IF and high MF scores. The thresholds of the geomorphological features were set according to the calculation formula. The maximum curvature was set higher than one to include only convex morphologies, like ridges and hills. The TPI included pixels with a threshold higher than zero. The value was set to include mostly unimpaired, as well as heavily-eroded ridges, but to delete valley filling debris and river sediments.
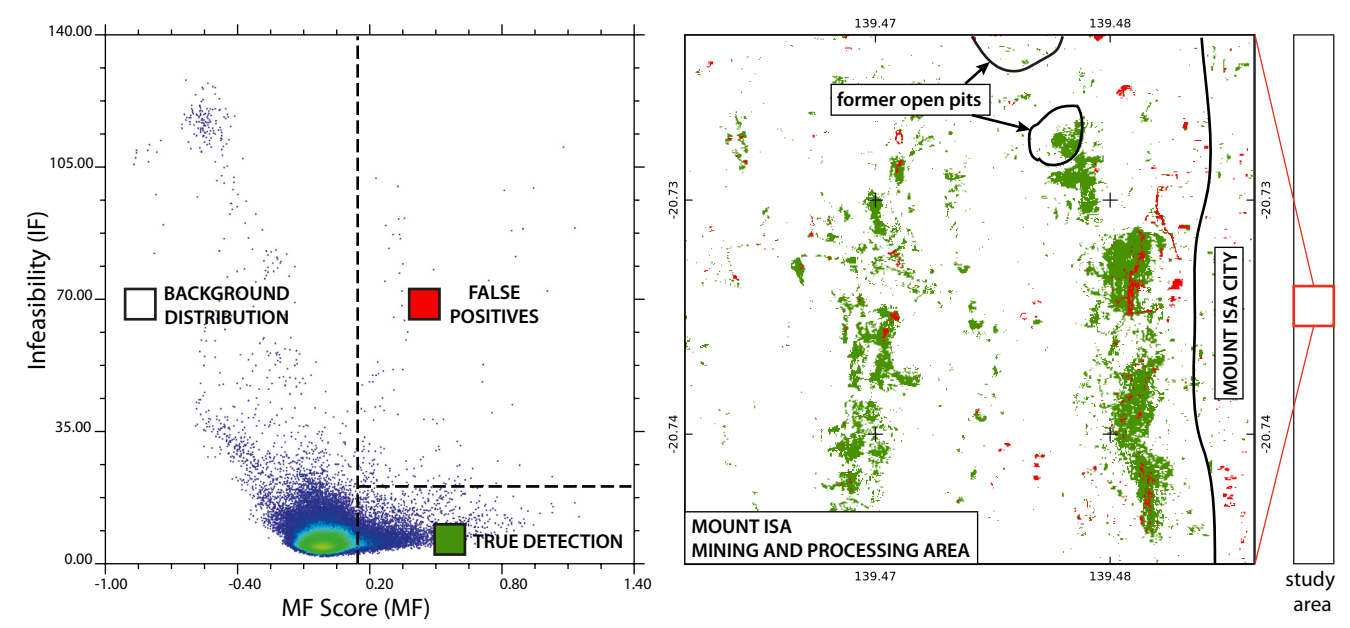

Figure 4. Left: 2D-scatter plot between the matched filtering (MF) score and infeasibility of a Mixture tuned matched filtering (MTMF) analysis. The dashed lines represent the thresholds for the discrimination between true detection, false positives and background distribution. Right: Visualization of true detection, false positives and the background distribution for the MTMF mapping of ironstone ridges at Mount Isa mine. 


\subsection{X-Ray Diffraction and Fluorescence Spectroscopy}

For a qualitative mineralogical compositional analysis of rock samples, a PANalytical Empyrean powder X-ray diffraction (P-XRD) was used. The Bruker S1 TITAN portable XRF (X-ray fluorescence) analyser was used for a qualitative elemental analysis. Even if the portable XRF detector does not reach the accuracy and reliability of a laboratory standing unit, it can be used in the field to give an approximate statement about the composition of the sample and the quantities of the contained elements.

\section{Preparation and Fieldwork}

The ore bodies of the Mount Isa mine deposit find their surface expression as silicified and ferruginous gossanous ridges within the Urquhart Shale. Therefore, in the preparation of the fieldwork, iron oxides were mapped from the HyMap data using library spectra endmembers to determine good sampling sites. Several north-south trending ferric iron features were detected not only within the common Urquhart shale near the mining sites, but also south of the mining area. The result coincides with the mineral map of the ferric iron content published by Cudahy et al. [13]. In July and August 2014, a three-week field study over four areas of Mount Isa Inlier was carried out, including the Mount Isa mining complex. A main objective was ground truthing of the previous remote sensing results and observations, including spectral measurements and rock sampling for the determination of suitable endmember pixels for a more precise mapping of the gossanous ridges. The field sampling was limited extremely by the prohibited access of large parts of the mining area to the west of Mount Isa (Figure 5). It limited the sampling sites for known Urquhart shale to one outcrop to the north of George Fisher mine and a spot near Mount Isa mine that could be visited during a guided tour (see Figure 6). Other limits were set by the rough topography, harsh vegetation and limited accessible tracks, which decreased the amount of visitable sites. For spectral measurements in the field, a Spectral Evolution PSM-3500 High Resolution Full Range Portable Spectroradiometer was used. It measures wavelengths between 350 and $2500 \mathrm{~nm}$. The spectral resolution (FWHM (full width at half maximum)) depends on the wavelength range and varies between $3 \mathrm{~nm}$ at $700 \mathrm{~nm}, 8 \mathrm{~nm}$ at $1500 \mathrm{~nm}$ and $6 \mathrm{~nm}$ at $2100 \mathrm{~nm}$. The measurements can either be taken with a contact probe with active illumination or with $1^{\circ}$ and $4^{\circ}$ lenses with passive illumination. During the field work, all together, 61 rock samples were collected. They contain specimens from nearly all important lithologies occurring within the area of interest. All samples originate from the surface and are often altered. The contact probe of the field spectroradiometer was used to take measurements from each specimen, considering both fresh fracture planes and altered parts.

According to the previously-calculated ferric iron mineral maps, two promising and accessible regions were visited, one $24 \mathrm{~km}$ south of Mount Isa mine and one bordering north to George Fisher/Hilton Mine (Figure 5). While the northern part lies within the host rock of the Mount Isa deposits, the southern site is located outside the mapped Urquhart Shales and was not given as a prospective site in any map. Indeed, at both places, matching gossanous ridge-like structures were found during the field work. Rock samples and spectral measurements were taken at each site. Both ridges extend in a north-south direction. The southern one runs along a low hill, which rises approximately 5-10 m over the adjacent alluvial flats. The outcrop itself forms a 1-5 $\mathrm{m}$ high wall-like structure on top of the hill, covering the hillsides with its debris. While the outcropping rock wall is a maximum of $10 \mathrm{~m}$ wide, the belonging hill ridge accounts for 150-200 $\mathrm{m}$ of width. The rock appears strongly altered and weathered, consisting mainly of a chert-like matrix with a thick black and ocher alteration crust. In most places, a lamination-like layering is still visible. The ridge can be traced north and south with interruptions over several attaching hills. Despite the strong resemblance to the gossanous ridges of the Urquhart Shale, this ridge is mapped in Grimes et al. [24] as the border between the Native Bee Siltstone in the east and Breakaway Shale in the west. 


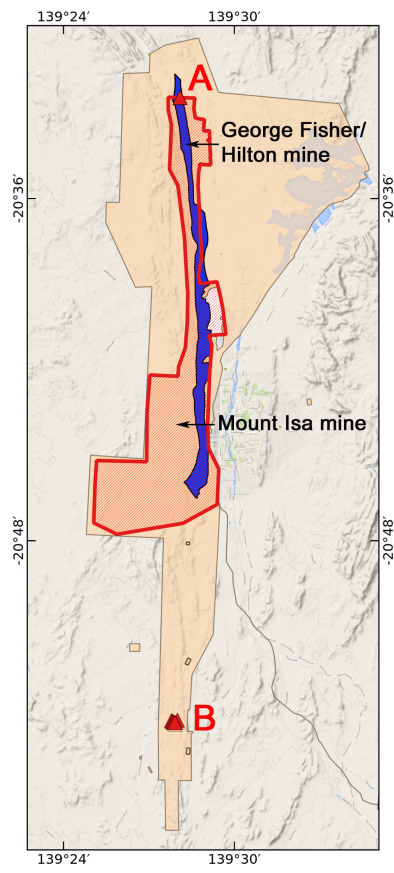

- Sample sites

Fenced/prohibited area

$\square$ Urquhart Shale

$\square$ Listed mining lease
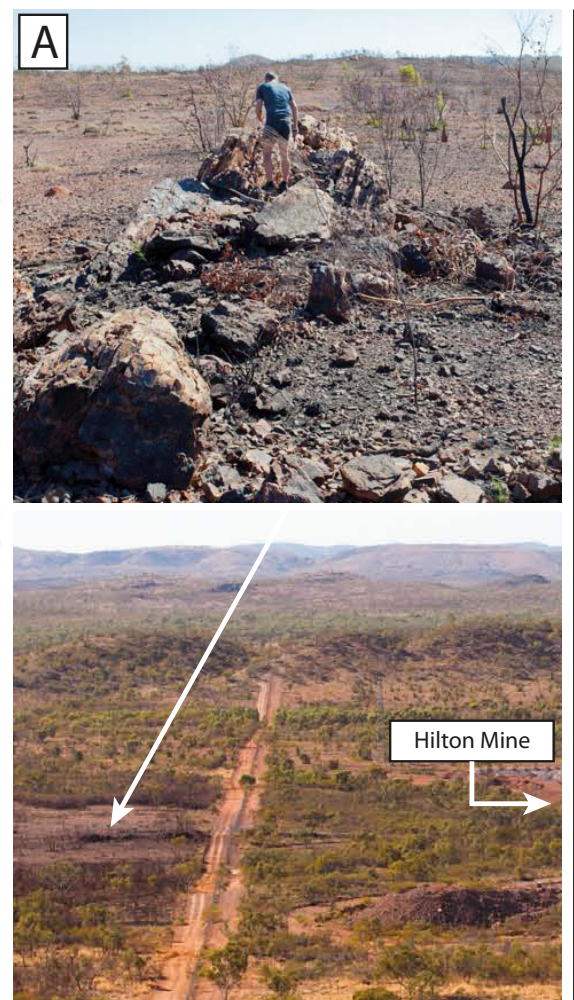
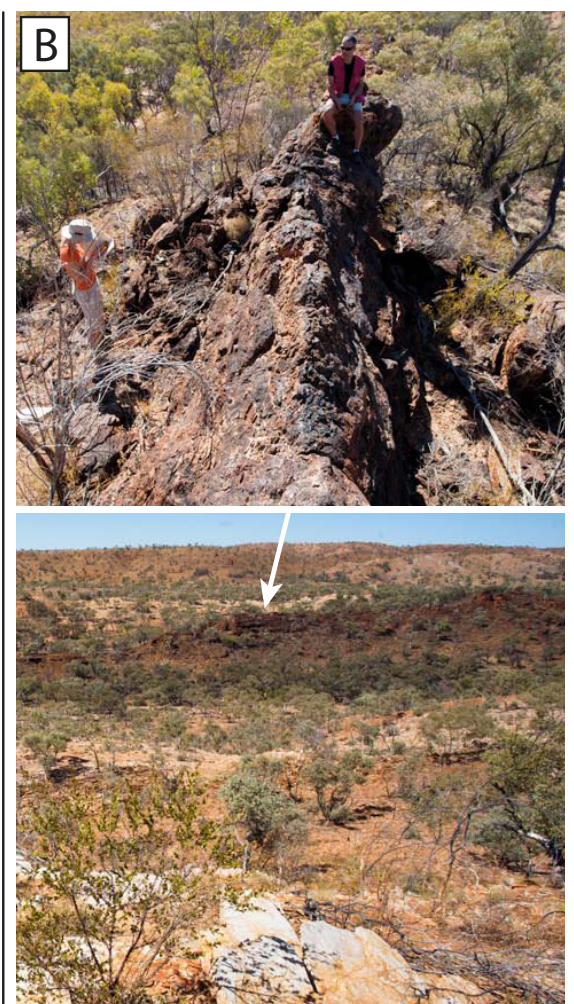

Figure 5. Ironstone ridges in the field: (A) gossanous outcrop at the north border of the Hilton mine area; (B) ridge $24 \mathrm{~km}$ south of Mount Isa mine. The map on the left shows the accessibility of the area as it was observed during the field work and the location of the sample sites. The mining lease is shown as given by Queensland Government, Department of Natural Resources and Mines [33].

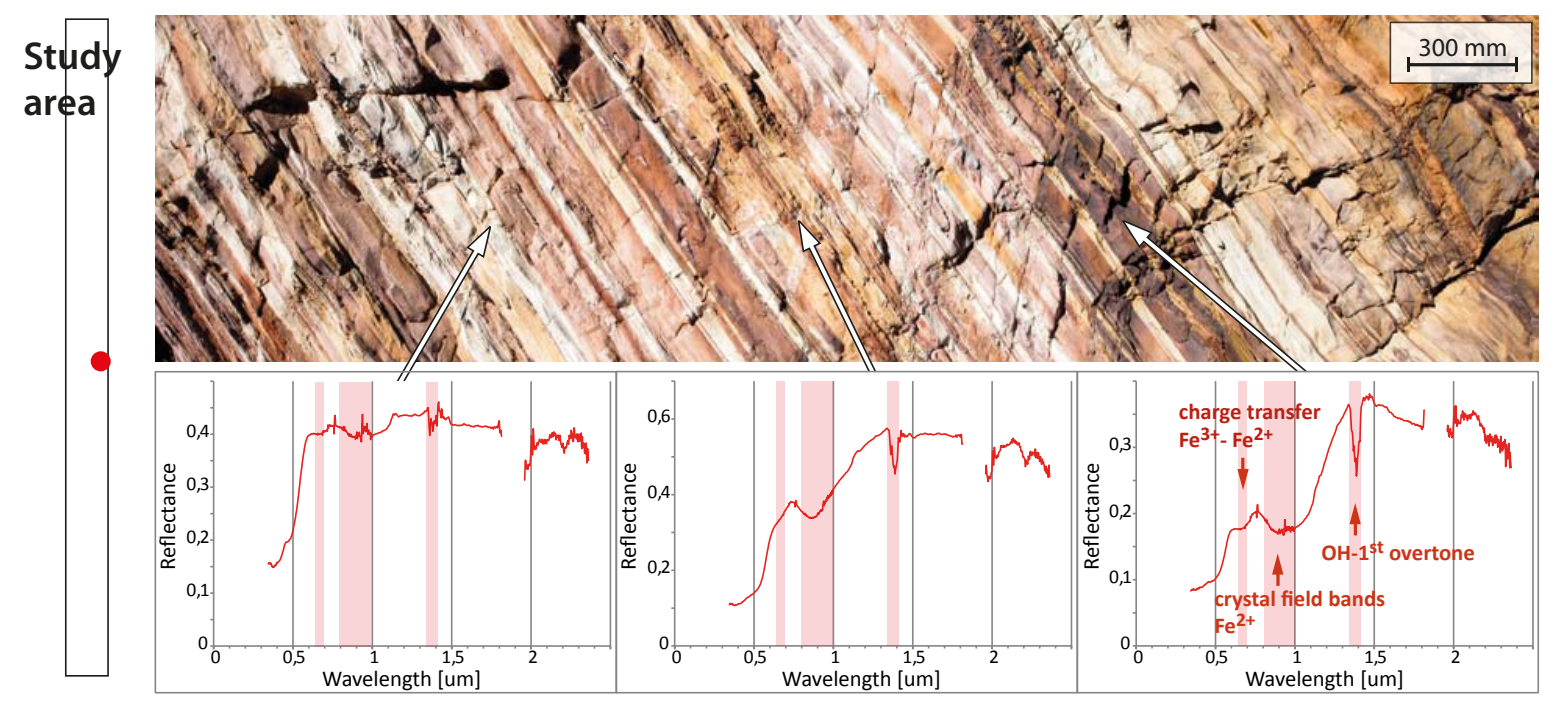

Figure 6. Series of altered mineralized and unmineralized horizons of the Urquhart Shale at an outcrop under a bridge near Mount Isa mine $\left(-20.700^{\circ} \mathrm{N}, 139.484^{\circ} \mathrm{E}\right)$. White to grey layers comprise unmineralized shales; ocher, reddish and dark sequences increasingly contain iron oxides and hydroxides due to altered previous mineralization. The spectra were taken using a field spectroradiometer with a $1^{\circ}$ lens at a $30-\mathrm{cm}$ distance (sample point $=2.6 \mathrm{~mm}$ ). 
The ridge adjacent to Hilton mine is comparably small and situated on a relatively flat plain within the Urquhart Shale. The height of the ridge seldom exceeds 1-2 $\mathrm{m}$. The general rock appearance is similar to the southern ridge, but with a lower amount of black-ocher ferruginous crusts or layers. The main part of the ridge is likely to represent the unmineralized parts of the Urquhart Shale; only the eastern sidewall is as strongly silicified and ferruginous as the southern ridge. Furthermore the extent of the outcrop is much smaller and more difficult to follow due to frequent interruptions and the low height.

The southern ironstone ridge was crossed during a transect. The different lithological units were sampled and measured with the field spectrometer. Thereby the observations focused on the presence of altered mineralized rock at the sampling points.

\section{Results}

The field spectrometer measurements proved that mineralized and unmineralized altered shales can be differentiated by the occurrence and depth of specific spectral absorption features. As is visible in Figure 6, the abundance of absorption features of ferrous and ferric iron ( 700 and $900 \mathrm{~nm})$ and hydroxide $(\sim 1450 \mathrm{~nm})$ indicates the occurrence of altered mineralization (see also Table 1), which is characterized by the presence of characteristic iron oxides, especially goethite and haematite [14]. The absorption feature depth increases with higher initial mineralization grade.

One characteristic rock sample of the mineralized shale in the south was analysed with XRD at four spots to determine the minerals present. The spots and the determined minerals are shown in Figure 7.
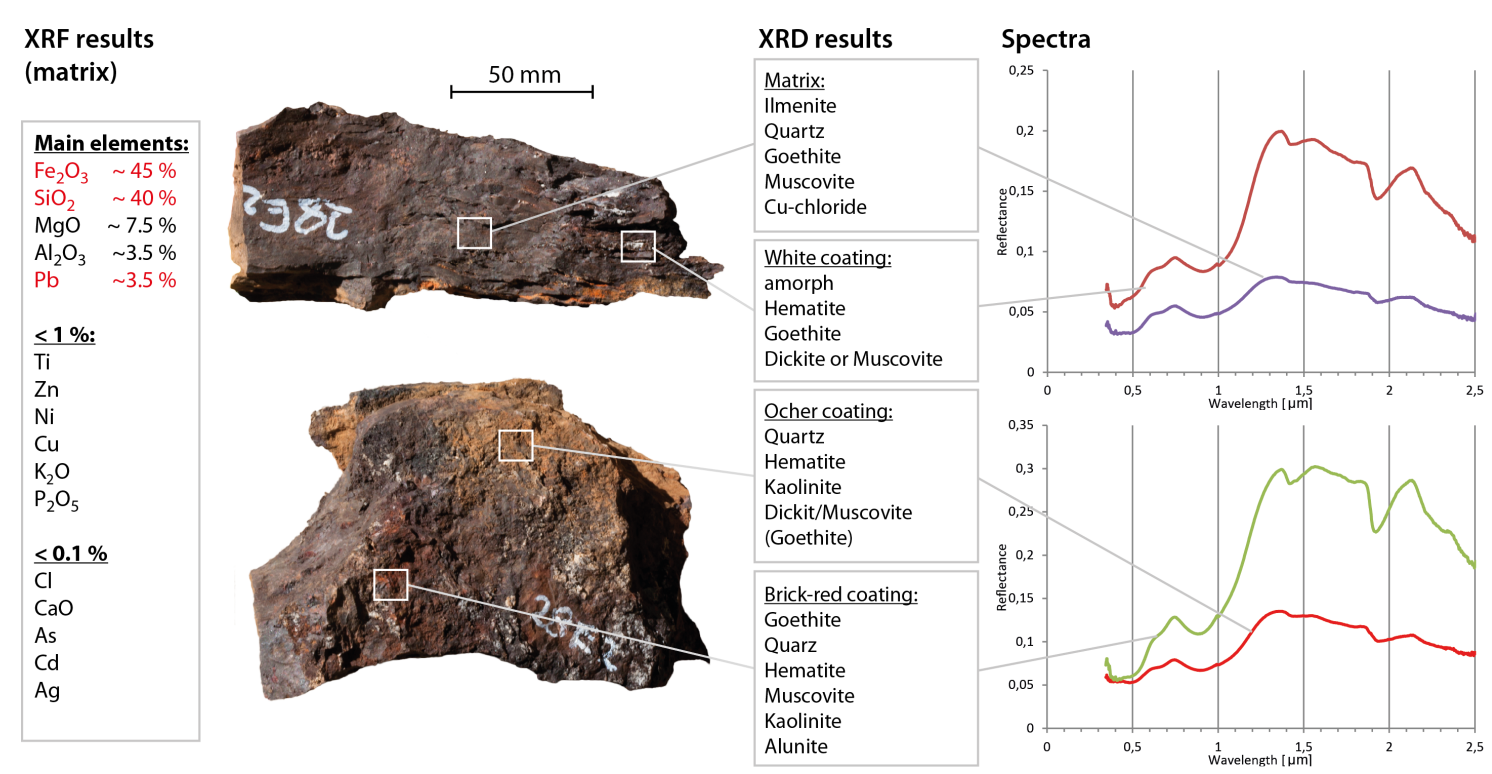

Figure 7. Results of the XRD- and XRF- analysis and in situ spectral measurements of a sample of the southern ridge. The spectra were measured using the field spectrometer with the contact probe, resulting in a probed sample of about $1 \mathrm{~mm}$ in diameter.

The matrix consists mainly of ilmenite, quartz, goethite, muscovite and $\mathrm{Cu}$-chloride; the coatings contain region-typical alteration products, like different iron oxides (haematite, goethite), further alunite and kaolinite. All six ridge samples were additionally examined using the Bruker S1 TITAN portable XRF analyser for a qualitative analysis of the occurring elements. The results for the characteristic sample are displayed in Figure 7. The recognized elements and compounds coincide largely with the minerals revealed by the XRD analysis. Besides the expected high amounts of iron oxide and silica, which are typical for the ferruginous and silicified ridges within the study area, a distinct $\mathrm{Pb}(-\mathrm{Zn})$-mineralization could be observed; additionally, noticeable amounts of titanium, nickel 
and copper. The determined traces of arsenic, silver and cadmium, as well as the exact concentrations have to be considered carefully, regarding the accuracy of the measurement. Similar compositions were measured for all of the mineralized samples of the northern and southern ridge, but with differing mineralization grades.

Due to differences referring to spectral resolution, noise, illumination and especially pixel size/field of view, the spectra measured in the field could not be used directly as input endmembers for the unmixing of the HyMap data using an MTMF method. To map the gossanous outcrops of the mineralized shale, their characteristic spectrum needed to be defined as the endmember from those HyMap pixels that coincide with the field-proven occurrence of the ironstone ridges. Considering the HyMap spatial resolution of $2.5 \mathrm{~m}$, only those pixels were used, which are typical for the target material and include almost no spectrally-interfering materials, such as soil and vegetation. Fieldwork with spectral and XRD and XRF analysis helped to identify those spots and resulted in two assured and representative input pixels, one of each field-observed ridge. The resulting endmember spectrum is plotted in Figure 8.

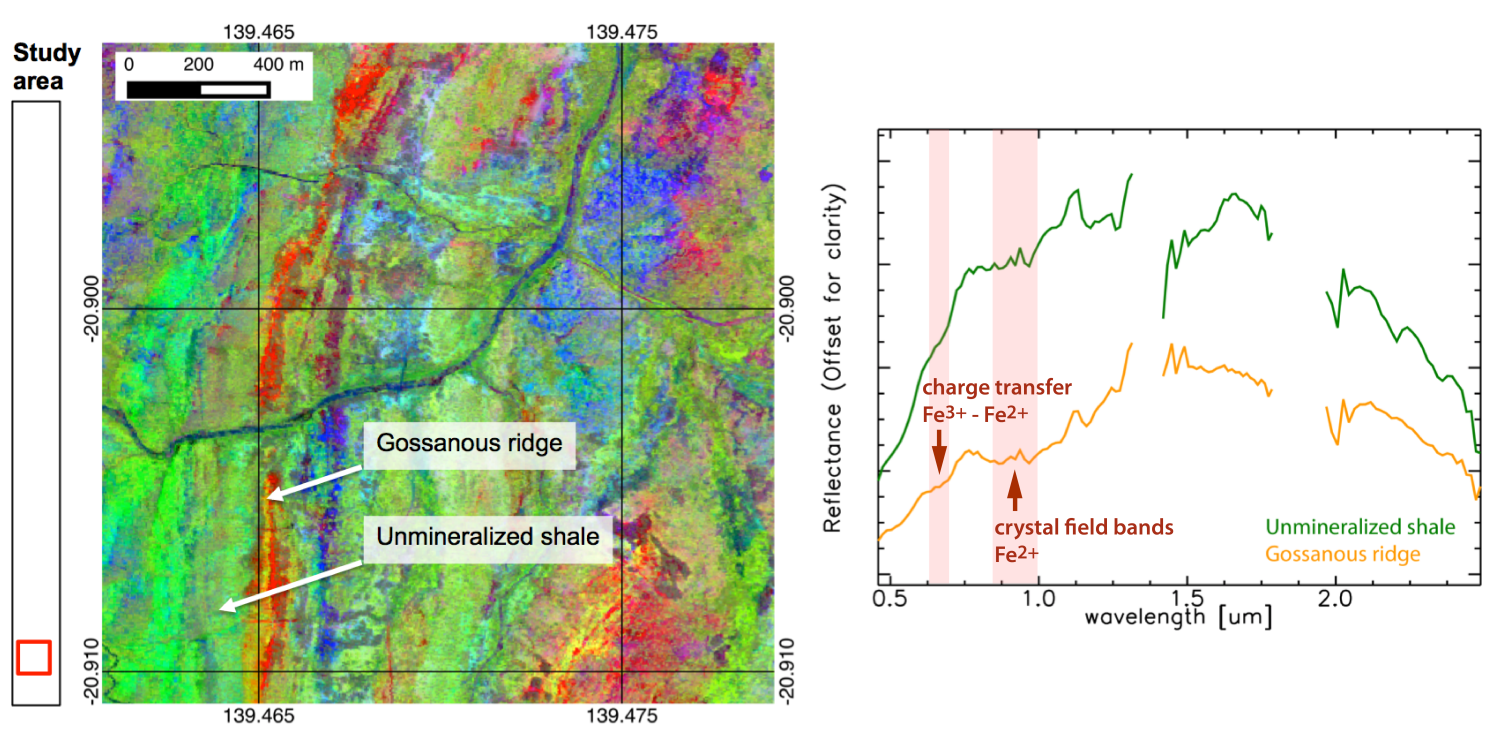

Figure 8. Left: HyMap minimum noise fraction (MNF) image (Bands 5, 7, 6) of the southern ironstone ridge. Right: HyMap endmember spectrum used for the MTMF mapping of the gossanous ridges (sample size: two pixels), compared to the HyMap spectrum of unmineralized shale (sample size: 10 pixels).

The 2D scatter plot (Figure 4) between MF score and infeasibility reveals a good mapping result due to the low number of false positives. The few occurring false positives are mostly related to buildings and sealed surfaces. They were masked out by setting a maximum threshold for the infeasibility value of 20, including only the horizontal bar of true detections across the bottom of the scatter plot. For the MF score, a minimum threshold of 0.15 was set according to the scatter plot to remove background distribution (Figure 4). The resulting image exhibits several long and small, parallel, north-south-trending ridges south of Mount Isa mine, which coincide with the structures observed during the fieldwork. The ridges can be mapped with interruptions about $45 \mathrm{~km}$ north, till the Spring Creek Fault cuts the Mount Isa succession east-west. Along the way, they traverse the mining areas of the Mount Isa and George Fisher/Hilton mines. Thereby, the usage of pixels only from the northern or only from the southern ridge exhibits results similar to using both ridges as input.

Figure 9 shows the results of the topographic analysis. TPI was calculated using a radius of 21 pixels, maximum curvature with a moving window of $7 \times 7$ pixels. Those parameters were chosen after a test series to determine values that lead to the best enhancement of the studied ridges. 
Higher values enhanced only large-scale structures, and the respective index was therefore no longer able to detect the gossanous ridges. Smaller values decreased the width of the detected gossanous ridges and, with that, lowered their enhancement. With the optimal parameters, both methods reveal a series of parallel, north-south striking structures, only interrupted by a few river beds, which bend NNW in the northern part of the observed area. To improve the mapping result, a decision tree was built, considering spectral, as well as spatial characteristics of the mineralized ridges (Figure 10). Due to the small amount of training sites (two pixels, one class), other promising classification methods like random forests do not apply here. The classification outcome was improved by sieving, which is used to remove isolated pixels from the classification image. The resulting classified ridges are displayed in Figures 9 and 10 (represented by Class 3). About one third of the MTMF detected pixels (9954 of 20,821 px) were removed from the mapping result by the implementation of geomorphological features with the decision tree. Most of the deleted pixels belong to roads, river fillings and irregular structures. Only a minor part regards border zones of the detected ridges.

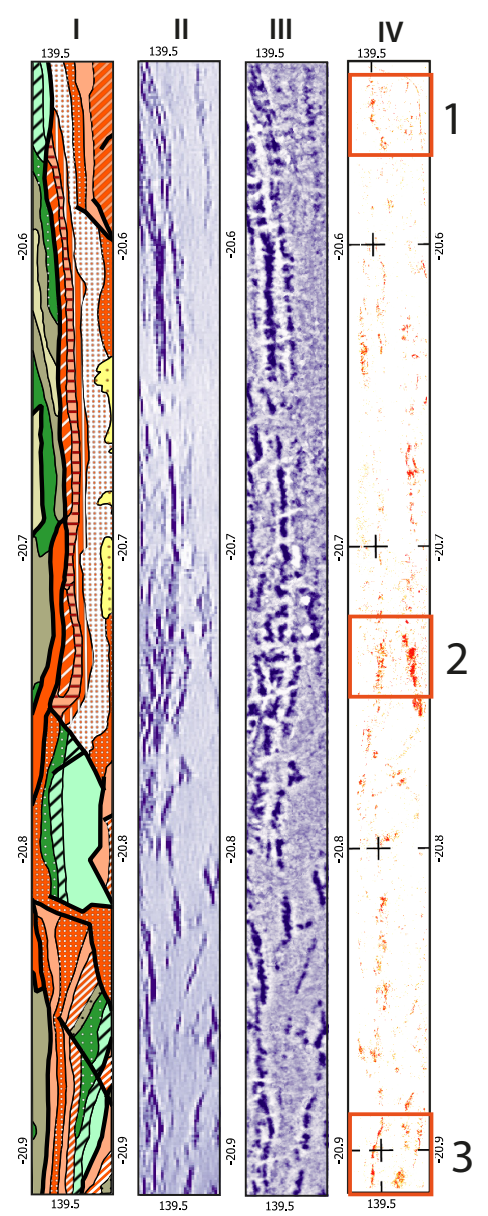

Decision tree mapping:
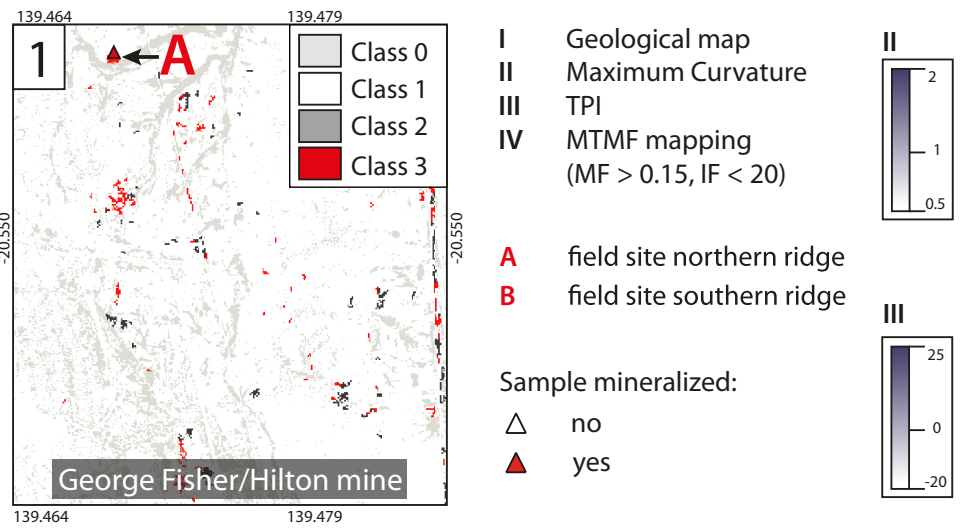

A field site northern ridge

B field site southern ridge

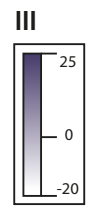

Sample mineralized:

$\triangle$ no

$\triangle$ yes
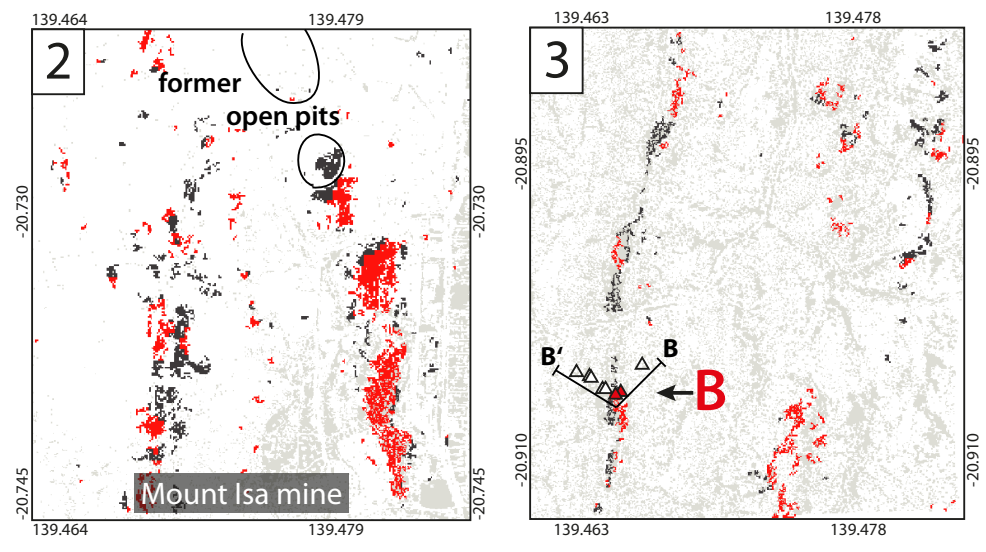

Figure 9. Mapping of the ironstone ridges. Classes of the decision tree results as indicated in Figure 10. 

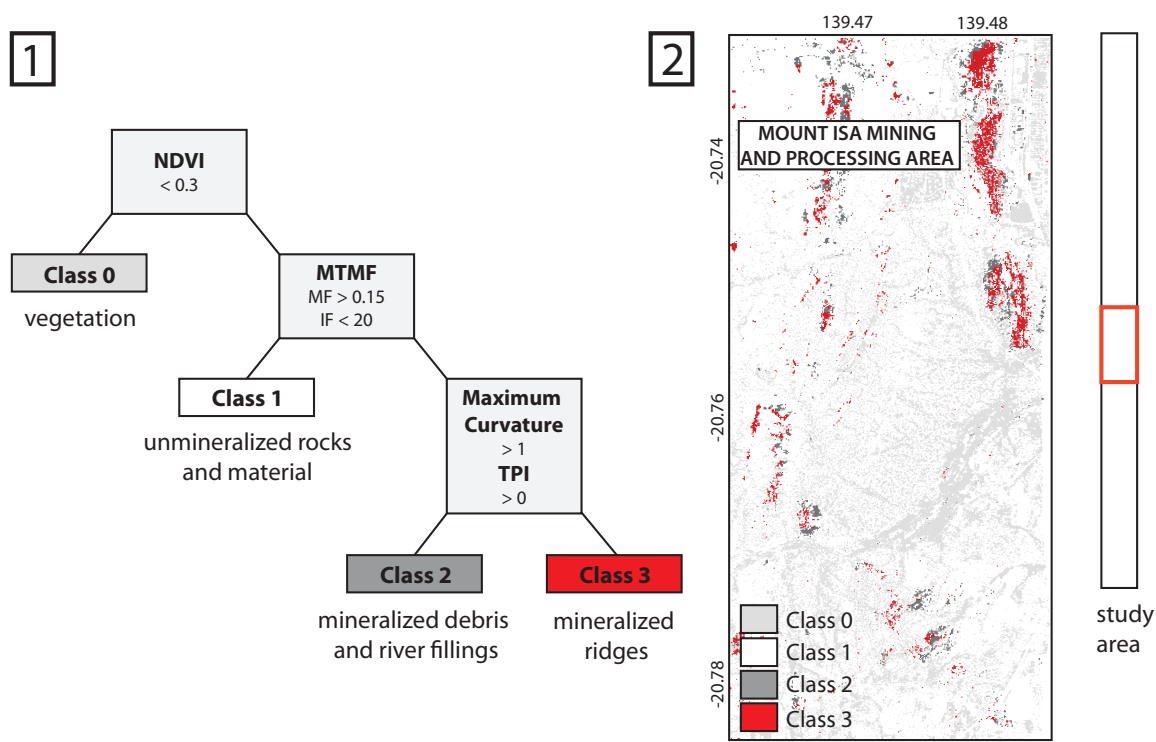

Figure 10. Mapping of the ironstone ridges using a decision tree: (1) decision tree scheme; (2) classification result of a part of the study area with Class 3 representing the mapped ironstone ridges.

\section{Discussion}

\subsection{Validation}

Due to the very low amount of in situ sites along the very narrow ridges, no significant accuracy percentage can be calculated. Nevertheless, there are indicators that attest to the rightness of the mapping result: The MTMF analysis was carried out three times under similar conditions, using either only the north, only the south and both training sites. The single results showed almost no difference, which indicates the spectral conformity of the northern and southern ridge, as well as the robustness of the mapping. A profile over the southern gossanous ridges proves that, despite the low spatial resolution of the ASTER GDEM, the TPI is able to detect the gossanous ridges (Figure 11) and coincides with the high MF score over the ridge. Clearly visible is the enhancement of the central part of the ridge in the MTMF result, regarding the gossanous outcrop on top of the hill ridge. Pixels with decreased, but positive MF score surrounding the ridge could indicate debris and are eliminated when considering the geomorphological features. For validation, the decision tree result was compared to the mineralization status of the sample points given in Figures 9 and 11. The occurrence of mineralized samples coincides 100\% with the positive classification result (pixels mapped as ironstone ridge), as well as the non-mineralized sample points concur with the negative classification result. In a post-processing stage, the ridge at the southern sampling site could be identified as part of the Mount Novit range, a sub-economic lead-zinc deposit, that is at least superficially similar to the Mount Isa and Hilton deposits and also strongly related to the Paroo fault [21,22]. The known extents and the quantitative chemical and mineralogical composition show a high coincidence to the results of this study. 


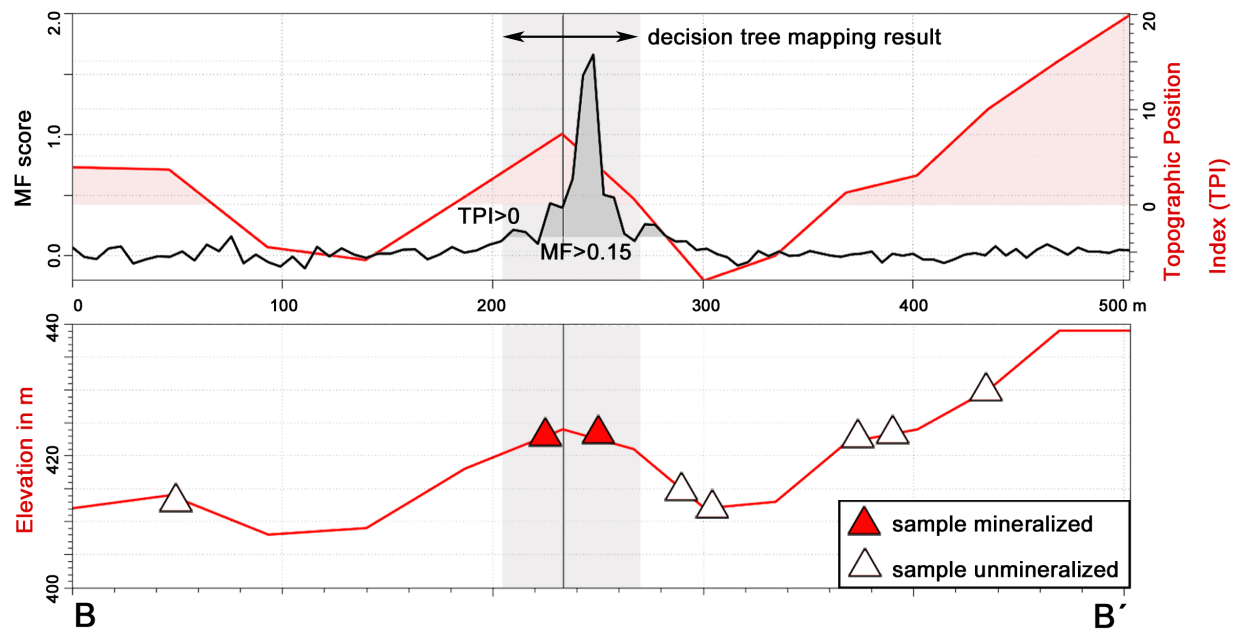

Figure 11. Profile crossing the southern ironstone ridge comprising elevation, MF score, topographic position index (TPI) (window size $21 \times 21$ pixels), sampled points and the consequent decision tree mapping result using the given thresholds. The profile location is indicated in Figure 9.

\subsection{Regional Outcomes}

Two mineralized ridges were observed during the field work. Measured reflectance spectra of the ridges show similar absorption features to the altered small, dark and mineralized stratigraphic horizons observed within the unmineralized Urquhart Shale near Mount Isa mine. These observations coincide with the statements made by Yang et al. [14], who used HyMap data for mineral mapping of the Mount Isa area. They stated that the observed high abundance of stratabound iron oxides is related to former sulphide mineralisation and is mainly characterized by haematite and goethite spectral features. Similar results were obtained by Cudahy et al. [13], who used the same dataset for alteration mineral mapping in several parts of the Mount Isa Inlier. The mentioned mineralized horizons form $\mathrm{Pb}-\mathrm{Zn}-\mathrm{Ag}$ deposits whenever they reach a certain density. The chemical and mineralogical composition of the deposit-related gossanous, silicified outcrops coincides with the observed ridges. Therefore, considerable amounts of up to $3.5 \% \mathrm{~Pb}$ and lower concentrations of $\mathrm{Ti}, \mathrm{Zn}$ and other metals were detected in the samples of the southern ridge. The MTMF mapping of rocks with a similar composition revealed that both ridges are connected by an interrupted chain of nearly parallel similar ridges trending north-south and crossing the mining areas of Mount Isa and George Fisher/Hilton. Thereby, the mapped location of the two observed ridges coincides completely with the occurrence of mineralized rock samples taken during the field work. The topographic analysis of the study area revealed several parallel geomorphological structures, bearing north-south and bending NNW in the north of the region. This bearing coincides with the faults shown in the available maps and with the course of the stratigraphic units of the Mount Isa Group. TPI and maximum curvature feature a slight, but noticeable increase along the mapped ironstone ridges (Figure 9 and 11). This suggests a relationship between the spectrally-mapped ridges and the north-south trending structures detected using geomorphological indices. The parallelism of ridges, faults and lithology indicates a connection to the mineralized horizons within the Urquhart Shale, which are stratabound, as well as influenced by and bound to the Mount Isa and Paroo fault system. The results indicate general similarity between the ironstone ridges at Mount Isa, Hilton and Mount Novit, even if they are hosted by different lithological units. This coincides with the conclusions drawn by [21].

\subsection{Methodological Outcomes}

Only a few samples were available for XRF and XRD analysis. Therefore, the determined components and concentrations should not be considered representative for the whole unit. However, 
even if a quantitative and robust analysis is not possible, the investigation of the samples can provide the qualitative chemical and mineralogical composition of the observed sample sites. An additional in situ observation and sampling of the now mapped ridges could be a good opportunity to validate the outcomes of the ridge mapping. The low number of false positives and the clear mapping of the ridges without a great dispersion suggest a good result. Additionally, the robustness of the result and the spectral similarity of the northern and southern ridge could be stated due to the similarity of the outcomes of three mapping attempts, using only the northern ridge, only the southern ridge and pixels from both sites as training sites. The observed southern ridge turned out to indeed be a known $\mathrm{Pb}-\mathrm{Zn}$ deposit, the extent of which coincides with the mapping result.

The geomorphological analysis provided promising results, which enhanced the generally north-south trending ridges and structures that follow the present faults and lithologies.

In general, the incorporation of geomorphological data as a support for spectral mineral mapping was a success. Even with the very small amount of two training pixels, the mapping returned quite solid results, which include the biggest known ironstone ridges at Hilton, Mount Isa and Mount Novit. The combination of spectral and spatial information using a decision tree refined the mapping result distinctly. Despite the low resolution of the digital elevation model, the geomorphological indices are able to detect the ridge structures when the right parameter values are chosen (Figure 11). Most valley fillings and debris could be removed from the mapping result, as well as pixels, which show similar spectral features as the mineralized ridges, but belong not directly to them, such as roads and river sediments. Even though previous knowledge is needed to define the thresholds of the decision tree, the method is quite easy and quick to operate and delivers reliable results. Nevertheless, there seem to be issues with pixels of heavily eroded or flatter parts of the ridges. Some of them were mapped with MTMF, but deleted during the decision tree classification process due to their missing expression within the DEM and their resulting similarity to debris or valley fillings. A good example for that is the high amount of dark grey pixels at the Mount Novit ridge site (Figure 9). Those pixels indicate parts of the ridge mapped by MTMF, but deleted by the geomorphological analysis. However, the observations made in the field justify most of the deletions, as those parts mainly comprise flat, debris-covered hill parts, where no original outcrop is visible any more. To further improve the classification result, the incorporation of spatial coordinates in the classification process would be advisable, but for that, an increased size of training sites would be needed. Another approach would be the usage of higher resolution digital elevation models, such as TerraSAR or drone photogrammetry data. Such DEMs could be able to consider even very small or heavily-eroded ridges and lead to a better mapping.

\section{Conclusions}

This contribution aims to showcase that mineral mapping and the exploration of mineral deposits can benefit from the integration of geometric information in a remote sensing study without the need of an extensive in situ sampling. This approach is especially dedicated to the investigation of structurally-related mineralization in remote or inaccessible areas and for the pre-selection of sites for exploration purposes. Such a scheme will allow one to decrease the exploration costs and the impact on the environment by increasing the efficiency of subsequent fieldwork, as well as the drilling-, geophysical- and mineralogical- surveys.

The spectral mapping was accomplished using hyperspectral HyMap data, whose high spatial and spectral resolution is best suited to detecting relevant characteristic features of altered mineralization. A thorough field campaign delivered crucial information for the selection of significant HyMap pixels as the endmember spectrum for MTMF mapping. Additionally, it provided important observations on the relationship between mineralization and morphology. We utilized this detected connection to set optimal parameters for the mapping of those geomorphological features using topographical indices on ASTER GDEM data. Due to the low amount of available training sites, the combined spectral and morphological mapping was accomplished using a knowledge-based decision tree classification. 
We demonstrated that the incorporation of morphometric features to the spectral data in a joint classification process can significantly improve the mapping of structurally-controlled mineralizations distinctly. Geomorphological data allow the distinction of surface materials with similar spectral features, but outcropping in a different morphological context. We used this additional information to successfully discriminate mineralized ridges from spectrally-similar structures, such as nearby valley filling debris in the Mt-Isa area in Australia. We increased the classification accuracy of specific geological units having economic potential by $30 \%$ combining spectral and geomorphological features compared to using spectral data only. The combined mapping study revealed a set of north-south trending ridge-like structures, which are similar to the gossanous, silicified outcrops of the Mount Isa typical Pb-Zn-Ag-deposits described in Conaghan et al. [9]. The geological features cross the Mount Isa and George Fisher/Hilton mines and also include the Mount Novit range deposit, which was identified without a priori knowledge in the present study. The sampled sites coincide in their general chemical and mineralogical composition with the lead-zinc mineralized gossans described by [21]. Additionally, these mapped units show a connection to the north-south trending geomorphological features.

The success of the presented approach is influenced by the size of the morphological units of interest in relation to the spatial resolution of the hyperspectral, as well as digital elevation data. We showed that it is possible to enhance ridges of a 100-200-m width using ASTER GDEM data, but the use of a higher resolution DEM could improve the mapping accuracy, especially for small-scale or heavily-eroded geological structures. We are currently testing the contribution of photogrammetric DEM acquired by lightweight unmanned airborne vehicles (UAV) for this purpose. Acquiring these data could be part of a future subsequent study in the Mt. Isa region. Additionally, a second fieldwork campaign would give us the opportunity to validate the current mapping results and to increase the amount of training pixels in key, but remote areas.

Acknowledgments: The authors want to thank the Commonwealth Scientific and Industrial Research Organization (CSIRO) for the sharing of data and information. We want to thank especially Sanaz Salati and Carsten Laukamp for the collaboration and support during the preparation of the study and the comments on the draft. Additionally we want to appreciate the support given by XSTRATAgeologist Tony Cleeton during the field work. We also highly appreciate the help of Robert Möckel, who provided the XRD analysis results. We would also like to thank Robert Thorne for the helpful comments on the draft. The study was financed by the Helmholtz Foundation.

Author Contributions: All authors contributed in a substantial way to the manuscript. S. Jakob performed analysis and interpretation of remote sensing and validation data and wrote the manuscript. R. Gloaguen and C. Laukamp reviewed and edited the manuscript. C. Laukamp provided the remote sensing data and helped with logistical support. Fieldwork was conducted by S. Jakob and R. Gloaguen in 2014. R. Gloaguen supervised the study at all stages.

Conflicts of Interest: The authors declare no conflict of interest.

\section{References}

1. Bedini, E. Mapping lithology of the Sarfartoq carbonatite complex, southern West Greenland, using HyMap imaging spectrometer data. Remote Sens. Environ. 2009, 113, 1208-1219.

2. Brown, A.J.; Cudahy, T.J.; Walter, M.R. Hydrothermal alteration at the Panorama Formation, North Pole Dome, Pilbara Craton, Western Australia. Precambrian Res. 2006, 151, 211-223.

3. Laukamp, C.; Cudahy, T.; Thomas, M.; Jones, M.; Cleverley, J.S.; Oliver, N.H. Hydrothermal mineral alteration patterns in the Mount Isa Inlier revealed by airborne hyperspectral data. Aust. J. Earth Sci. 2011, 58, 917-936.

4. Hussey, M.C. HyMap Survey Processing Report: Musgrave Ranges, South Australia, January 2012. Hy Vista Corp. 2012. Available online: https://sarigbasis.pir.sa.gov.au/WebtopEw/ws/samref/ sarig1/image/DDD/GDP00002\% 20R1.pdf (accessed on 7 December 2014).

5. Azizi, M.; Saibi, H.; Cooper, G. Mineral and structural mapping of the Aynak-Logar Valley (Eastern Afghanistan) from hyperspectral remote sensing data and aeromagnetic data. Arabian J. Geosci. 2015, 8, 10911-10918. 
6. Bersi, M.; Saibi, H.; Chabou, M. Aerogravity and remote sensing observations of an iron deposit in Gara Djebilet, southwestern Algeria. J. Afr. Earth Sci. 2016, 116, 134-150.

7. Blake, D.H. Geology of the Mount Isa Inlier and environs, Queensland and Northern Territory; Bureau of Mineral Resources, Geology and Geophysics Bulletin; Australian Govt. Pub. Service: Canberra, Australia, 1987; Volume 225.

8. Grondijs, H.F.; Schouten, C. A study of the Mount Isa ores [Queensland, Australia]. Econ. Geol. 1937, 32, 407-450.

9. Conaghan, E.L.; Hannan, K.W.; Tolman, J. Mount Isa Cu and Pb-Zn-Ag deposits, NW Queensland Australia; Cooperative Research Centre for Landscape Environments and Mineral Exploration: Canberra, Australia, 2003. Available online: http://crcleme.org.au/RegExpOre/MtIsa.pdf (accessed on 7 December 2014).

10. Forrestal, P.J. Mount Isa and Hilton Silver-Lead-Zinc Deposits. In Geology of the Mineral Deposits of Australia and Papua New Guinea; Hughes, F.E., Ed.; The Australasian Institute of Mining and Metallurgy: Melbourne, Australia, 1990; pp. 927-934.

11. Stewart, A.J.; Blake, D.H. Detailed Studies of the Mount Isa Inlier; Australian Govt. Pub. Service: Canberra, Australia, 1992; Volume 243.

12. Wilde, A.R. Mount Isa copper orebodies: Improving predictive discovery. Aust. J. Earth Sci. 2011, 58, $937-951$.

13. Cudahy, T.; Jones, M.; Thomas, M.; Laukamp, C.; Caccetta, M.; Hewson, R.; Rodger, A.; Verrall, M. Next Generation Mineral Mapping: Queensland Airborne HyMap and Satellite ASTER Surveys 2006-2008; CSIRO Exploration \& Mining Report P2007/364; CSIRO Exploration and Mining: Perth, Australia, 2008.

14. Yang, K.; Huntington, J.F.; Quigley, M.; Scott, K.; Mason, P. Mapping the effects of regional metamorphism and hydrothermal alteration in the Mount Isa Valley, Queensland, Australia, using airborne hyperspectral data. In Proceedings of the 2003 IEEE International Geoscience and Remote Sensing Symposium, Toulouse, France, 21-25 July 2003; pp. 1555-1557.

15. Laukamp, C.; Cudahy, T.; Cleverley, J.S.; Oliver, N.H.S.; Hewson, R. Airborne hyperspectral imaging of hydrothermal alteration zones in granitoids of the Eastern Fold Belt, Mount Isa Inlier, Australia. Geochem.: Explor. Environ. Anal. 2011, 11, 3-24.

16. Perera, K.; Moore, D.; Tateishi, R.; Apan, A.; McDougall, K. Mapping Queensland land cover accordong to FAO LCCS using multi-source spatial data. Int. Arch. Photogramm. Remote Sens. Spat. Inform. Sci. 2010, 38, 742-747.

17. Etheridge, M.A.; Rutland, R.W.R.; Wyborn, L.A.I. Orogenesis and tectonic process in the early to middle Proterozoic of northern Australia. In Proterozic Lithospheric Evolution; Geodynamics Series; Kröner, A., Ed.; American Geophysical Union: Washington, DC, USA, 1987; Volume 17, pp. 131-147.

18. Weil, A.J. Mine geology, Mount Isa. In Proceedings of the Field Conference: Mount Isa, Mary-Kathleen Area, 10-12 June 1967; pp. 20-23.

19. Smith, W.D. The broader aspects of secondary mineralization at Mount Isa, Queensland. Proc. Australas. Inst. Min. Metall. 1966, 217, 33-38.

20. Betts, P.G.; Lister, G.S. Geodynamically indicated targeting strategy for shale-hosted massive sulphide $\mathrm{Pb}-\mathrm{Zn}$-Ag mineralisation in the Western Fold Belt, Mt Isa terrane. Aust. J. Earth Sci. 2002, 49, 985-1010.

21. Taylor, G.; Scott, K. Evaluation of gossans in relation to lead-zinc mineralisation in the Mount Isa Inlier, Queensland. BMR J. Aust. Geol. Geophys. 1982, 7, 159-180.

22. Perkins, W.G. A Study of the Nature, Timing, and Processes in the Mount Isa Lead-Zinc Orebodies; Their Relationship to Adjacent Copper Ore-Bodies and The Lead-Zinc Systems at Mc Arthur River, Hilton, and Mount Novit. Ph.D. Thesis, James Cook University of North Queensland, Queensland, Australia, 1996.

23. Wilson, I.H.; Grimes, K.G.; Derrick, G.M. Cloncurry, Queensland, 1:250 000 Geological Series Map: Sheet SF/54-02; Geological Survey of Queensland: Brisbane, Australia, 1983.

24. Grimes, K.G.; Hutton, L.J.; Wilson, I.H. Mount Isa, Queensland, 1:250 000 Geological Series Map: Sheet SF/54-02, 2nd ed.; Bureau of Mineral Resources, Canberra \& Geological Survey of Queensland: Brisbane, Australia, 1987.

25. Clark, R.N. Chapter 1: Spectroscopy of Rocks and Minerals, and Principles of Spectroscopy. In Manual of Remote Sensing; Rencz, A.N., Ed.; John Wiley and Sons: New York, NY, USA, 1999; Volume 3, pp. 3-58.

26. Cocks, T.; Jenssen, R.; Stewart, A.; Wilson, I.; Shields, T. The HYMAP airborne hyperspectral sensor: The system, calibration and performance. Presented at the 1st EARSeL Workshop on Imaging Spectrocopy, Zürich, Switzerland, 6-8 October 1998. 
27. Harsanyi, J.C.; Chang, C. Hyperspectral image classification and dimensionality reduction: An orthogonal subspace projection approach. IEEE Trans. Geosci. Remote Sens. 1998, 32, 779-785.

28. Mundt, J.T. Partial unmixing of hyperspectral imagery: Theory and methods. In Proceedings of the American Society for Photogrammetry and Remote Sensing-ASPRS Annual Conference 2007: Identifying Geospatial Solutions, Tampa, FL, USA, 7-11 May 2007; Volume 2, pp. 440-451.

29. Weiss, A.D. Topographic Position and Landforms Analysis; Presented at ESRI Users Conference, San Diego, CA, USA, 2001.

30. Reu, J.D.; Bourgeois, J.; Bats, M.; Zwertvaegher, A.; Gelorini, V.; Smedt, P.D.; Chu, W.; Antrop, M.; Maeyer, P.D.; Finke, P.; et al. Application of the topographic position index to heterogeneous landscapes. Geomorphology 2013, 186, 39-49.

31. Wood, J. The Geomorphological Characterization of Digital Elevation Models. Ph.D. Thesis, University of Leicester, Department of Geography, Leicester, UK, 1996.

32. Rouse, J.W.J.; Haas, R.H.; Schell, J.A.; Deering, D.W. Monitoring the Vernal Advancement and Retrogradation (Green Wave Effect) of Natural Vegetation; Progress Report RSC 1978-1; Texas A\&M University Remote Sensing Center: College Station, TX, USA, 1973.

33. Queensland Government, Department of Natural Resources and Mines. Queensland Spatial Catalogue, Mining Leases-Queensland 2015. Available online: http://www.qldspatial.information.qld.gov.au (accessed on 28 August 2015).

(C) 2016 by the authors; licensee MDPI, Basel, Switzerland. This article is an open access article distributed under the terms and conditions of the Creative Commons Attribution (CC-BY) license (http://creativecommons.org/licenses/by/4.0/). 